Original Article

\title{
Predictors of energy cost during stair ascent and descent in individuals with chronic stroke
}

\author{
Janaine Cunha Polese, PhD, $\mathrm{PT}^{1,2)^{*}}$, Aline Alvim Scianni, PhD, $\mathrm{PT}^{1)}$, \\ Luci Fuscaldi Teixeira-Salmela, PhD, PT ${ }^{1)}$ \\ 1) Discipline of Physiotherapy, Universidade Federal de Minas Gerais: Avenida Antônio Carlos, 6627, \\ Campus Pampulha, 31270-901 Belo Horizonte, Minas Gerais, Brazil \\ 2) Discipline of Physiotherapy, Faculdade de Ciências Médicas de Minas Gerais, Brazil
}

\begin{abstract}
Purpose] This study aimed to determine which clinical measures of walking performance and lower limb muscle strength would predict energy cost during stair ascent and descent in community-dwelling individuals with stroke. [Subjects and Methods] Regression analysis of cross-sectional data from 55 individuals between one and five years post-stroke was used to investigate the measures of walking (speed and distance covered during the 6-minute walk test [6MWT]), and strength of the paretic knee extensor and ankle plantar flexor muscles would predict energy cost during stair ascent and descent. [Results] Three predictors (habitual walking speed, distance covered during the 6MWT, and strength of the paretic knee extensor muscles) were kept in the model. Habitual walking speed alone explained $47 \%$ of the variance in energy cost during stair ascent and descent. When the strength of the paretic knee extensor muscles was included in the model, the explained variance increased to $53 \%$. By adding the distance covered during the 6MWT, the variance increased to $58 \%$. [Conclusion] Habitual walking speed, distance covered during the 6MWT, and strength of the paretic knee extensor muscles were significant predictors of energy cost during stair ascent and descent in individuals with mild walking limitations.
\end{abstract}

Key words: Stroke, Energy metabolism, Stairs

(This article was submitted Jul. 21, 2015, and was accepted Sep. 17, 2015)

\section{INTRODUCTION}

Energy cost during the performance of motor activities is one of the most important variables to be assessed ${ }^{1,2)}$, since increases in energy cost are related to poor movement efficiency may lead to reduced physical activity in individuals with stroke ${ }^{1,2)}$. Although the mechanisms are not fully understood $^{2}$, it is well known that the energy cost in individuals with stroke is higher than that observed for healthy individuals. This has a negative impact on walking performance, such as speed and endurance ${ }^{3}$. Given the potential negative impact of increased energy cost on daily activities, it is surprising that only a few studies have investigated this outcome.

Approximately half of individuals after stroke remain dependent on others for some daily activities, and $65 \%$ report restrictions in community reintegration ${ }^{4}$. Dependence on activities of daily living is an important issue, since physical limitations may lead to perceptions of poor quality of life ${ }^{5)}$ Alzahrani et al. ${ }^{6)}$ reported that the ability to ascend and descend stairs was the best predictor of physical activity levels

\section{*Corresponding author. Janaine Cunha Polese (E-mail:} janainepolese@yahoo.com.br)

C 2015 The Society of Physical Therapy Science. Published by IPEC Inc. This is an open-access article distributed under the terms of the Creative Commons Attribution Non-Commercial No Derivatives (by-ncnd) License $<$ http://creativecommons.org/licenses/by-nc-nd/3.0/>. in community-dwelling individuals with stroke. The frequent need to manage stairs in daily life makes the recovery of walking and stair climbing capacity the main rehabilitation goal for these individuals ${ }^{7)}$. Stair ascent and descent demand more effort, compared to level walking, since upward and forward forces are required to support body weight and the continuous ability to control limits of stability ${ }^{8}$. Improved ability to ascend and descend stairs could lead to increased community participation by individuals with stroke in places with stairs, such as supermarkets, churches, and parks ${ }^{9)}$. In addition, the ability to ascend and descend stairs was among the top five tasks that community-dwelling older adults rated as being the most difficult to perform ${ }^{10)}$.

Although stair ascent and descent ability is important for community participation, few studies have investigated aspects related to these tasks; these activities are better explored and emphasized in a clinical context, due to their importance for reintegration into the community ${ }^{11)}$. Given the need to use simple measurements, which are able to produce information transferable from clinical practice to real life, the purpose of this study was to determine which clinical measures of walking performance and lower limb muscle strength would predict energy cost during stair ascent and descent in community-dwelling individuals with stroke. Therefore, the specific research question was:

Which clinical measures of walking performance (speed and distance covered during the 6-minute walk test [6MWT]) and strength of the paretic knee extensor and ankle plantar flexor muscles would predict energy cost during stair ascent 
and descent in community-dwelling individuals with stroke?

\section{SUBJECTS AND METHODS}

For this cross-sectional observational study, participants were recruited from the local community and outpatient physiotherapy clinics from September to December 2014. The outcome measures were randomly collected over one day in a laboratory setting. This study was approved by the institutional ethical review board and all participants provided written consent prior to data collection.

People with stroke were included if they were $\geq 20$ years of age; were within 1 to 5 years after their first stroke; and were able to walk at least 14 meters independently, without walking aids. They were excluded if they had cognitive impairments, as determined by education-adjusted cut-off scores on the Mini-mental state examination (18/19 for illiterate individuals and $24 / 25$ for those with a basic education $^{12)}$ ), or any other neurological or orthopedic disorders.

Physiotherapists with at least 3 years of clinical research experience collected all measures. Demographic, anthropometric, and clinical characteristics of the participants, such as age, gender, side of weakness, time since the onset of stroke, plantar flexor muscle tone (modified Ashworth scale) ${ }^{13)}$, and functional independence (Barthel Index) ${ }^{14)}$, were collected for characterization purposes.

A minimum sample size of 50 participants was based on the formula proposed by Dohoo et $\mathrm{al}^{15}$. For this calculation, four independent variables were used in the multiple regression model.

The outcome of interest was oxygen cost during stair ascent and descent. Measures of oxygen expenditure in $\mathrm{ml} \cdot \mathrm{kg}^{-1} \cdot \mathrm{min}^{-1}$ were collected with a portable monitoring system (Metamax 3B; Cortex, Leipzig, Germany), while the participants ascended and descended a flight of stairs with 11 steps $(18 \mathrm{~cm}$ high and $30 \mathrm{~cm}$ deep) for 5 minutes. The measures of the last 2 minutes (steady state condition) were recorded and stored for analysis ${ }^{16}$. Oxygen cost was calculated by dividing the oxygen expenditure values by the distance covered in meters, and reported as $\mathrm{ml} \cdot \mathrm{kg}^{-1} \cdot \mathrm{m}^{-1}$. The distance covered was calculated as the hypotenuse of the stair height and depth $(35 \mathrm{~cm})$, multiplied by the number of steps/minute that the subjects ascended and descended during the last 2 minutes of the test.

The predictors included two measures of walking (speed and distance covered during the 6MWT) and two strength measures of the paretic lower limb muscles (knee extensors and ankle plantar flexors).

Habitual speed in $\mathrm{m} / \mathrm{s}$ was measured using the $10-\mathrm{m}$ walk test, which has shown adequate test-retest reliability for the stroke population ${ }^{17)}$, following standardized verbal commands ${ }^{18)}$. The participants were asked to walk $14 \mathrm{~m}$ on a level surface with their usual shoes, at a comfortable speed. The time to cover the central $10 \mathrm{~m}$ was recorded.

The distance covered, in meters, during the 6MWT was assessed, following the procedures and recommendations of the American Thoracic Society ${ }^{19}$ ). The 6MWT has shown adequate test-retest reliability for individuals with stroke ${ }^{20)}$. To ensure safety, the examiner stood close behind the participants during all walking tests.
The isometric strength of the paretic lower limb muscles in, kgf, was measured with the Microfet 2 hand-held dynamometer (Hoggan Health Industries, Draper, UT, USA), which provides reliable measures of strength in individuals with stroke ${ }^{21)}$. The strength of the paretic knee extensor and ankle plantar flexor muscles was assessed, following the recommendations of Dorsch et $\mathrm{al}^{22)}$. For all measurements, the participants lay supine, with their paretic lower limb placed on a stool at $90^{\circ}$ of hip and knee flexion, and the contralateral limb resting in neutral on a plinth. These muscular groups were chosen, due to the dominant role of the knee extensors in progression from one step to the next, assisted by the ankle plantar flexors, during stair ascent.

For descriptive statistics, tests for normality (Kolmogorov-Smirnov), and homogeneity of variance (Levene) were carried out for all outcomes. Pearson's correlation coefficients were calculated to examine the relationships (magnitude, direction, and significance) between the predictors and the energy cost during stair ascent and descent. Correlation analyses were used as the initial steps required for determining the variables for inclusion in the regression analyses. The strength of the relationships was described using the correlation coefficient $(r)$, and was based upon Munro's correlation descriptors ${ }^{23}$ ) (very low $=0.15-0.24$, low $=0.25-0.49$, moderate $=0.50-0.69$, high $=0.70-0.89$, and very high $=0.90-1.00$ ). These variables correlated with the energy cost were entered into the regression model. One prediction equation was developed from the coefficients (B). To be included in the prediction equation, the predictors had to be significant at $\mathrm{p}<0.05$ or had to explain an additional $5 \%$ of the variance.

\section{RESULTS}

A total of 142 eligible individuals with stroke were recruited by telephone. Of these, 31 (22\%) could not be reached and $56(39 \%)$ refused to participate. Therefore, 55 volunteers, including 33 males, agreed to participate. Their mean age was 59 years (SD 15) and their mean time since the onset of the stroke was 25 months (SD 14). The average of speed achieved during stair ascent and descent was 0.68 stairs/s. The characteristics of the participants and all outcomes are reported in Table 1.

The regression analysis showed that, three predictors (habitual walking speed, distance covered during the 6MWT, and strength of the paretic knee extensor muscles) were kept in the model (Table 2). Habitual walking speed alone explained $47 \%(F=34.8 ; \mathrm{p}<0.001)$ of the variance in the energy cost during stair ascent and descent. When the strength of the paretic knee extensor muscles was included in the model, the explained variance increased to $53 \%(F=22.8$; $\mathrm{p}$ $<0.001)$. By adding the distance covered during the $6 \mathrm{MWT}$, the explained variance increased to $58 \%(F=18.2 ; \mathrm{p}<0.001)$. Both walking speed and distance covered during the $6 \mathrm{MWT}$ were negatively correlated with the energy cost, whereas the strength of the knee extensor muscles was positively correlated. This indicated that people who had weaker knee extensor muscles, walked faster, and covered greater distances during the 6MWT showed lower energy cost values.

Therefore, the energy cost during stair ascent and descent 
Table 1. Characteristics of the participants

\begin{tabular}{|c|c|}
\hline Characteristic & $\mathrm{n}=55$ \\
\hline Age (years), mean (SD) & $59(14)$ \\
\hline Gender, $n$ males $(\%)$ & $33(6)$ \\
\hline Side of weakness, $n$ right (\%) & $34(62)$ \\
\hline Type of stroke, $n$ ischemic (\%) & $51(93)$ \\
\hline Time since the onset of the stroke (months), mean (SD) & $25(14)$ \\
\hline Body mass index (kg/m2), mean (SD) & $26(5)$ \\
\hline Cognition (MMSE score $0-30$ ), mean (SD) & $25(3)$ \\
\hline \multicolumn{2}{|l|}{ Muscle tone (Modified Ashworth Scale, 0-4), n } \\
\hline 0 & 35 \\
\hline 1 & 3 \\
\hline $1+$ & 3 \\
\hline 2 & 6 \\
\hline 3 & 2 \\
\hline 4 & 6 \\
\hline Functional independence (Barthel Index, 0-34), mean (SD) & $18(1)$ \\
\hline \multicolumn{2}{|l|}{ Predictors } \\
\hline Habitual walking speed (m/s), mean (SD) & $0.84(0.30)$ \\
\hline Distance covered during 6MWT (m), mean (SD) & $332(129)$ \\
\hline Knee extensor strength $(\mathrm{kgf})$, mean $(\mathrm{SD})$ & $9.6(4.1)$ \\
\hline Ankle plantar flexor strength (kgf), mean (SD) & $6.6(3.0)$ \\
\hline Outcome of interest: EC during stair ascent and descent $\left(\mathrm{ml} \cdot \mathrm{kg}^{-1} \cdot \mathrm{m}^{-1}\right)$, mean (SD) & $1.13(0.43)$ \\
\hline
\end{tabular}

could be predicted by the following equation: Energy cost $\left(\mathrm{ml} . \mathrm{kg}^{-1} \cdot \mathrm{m}^{-1}\right)=1.87-0.57$ (habitual walking speed in $\mathrm{m} / \mathrm{s}$ ) -0.01 (distance covered during the 6MWT in $\mathrm{m}$ ) +0.03 (strength of the paretic knee extensor muscles in kgf).

\section{DISCUSSION}

This study found that the energy cost during stair ascent and descent was predicted by three clinical measures: habitual walking speed, strength of the paretic knee extensor muscles, and distance covered during the 6MWT. These variables together explained over half of the variance of the energy cost during stair ascent and descent in individuals with chronic stroke.

The results of the present study demonstrated that habitual walking speed alone explained almost half of the variance in the energy cost during stair ascent and descent. Previous studies reported a curvilinear relationship between increases in walking speed and movement efficiency, determined by the energy cost during walking at various speeds in individuals with stroke $\mathrm{e}^{3,24,25)}$. However, to the best of our knowledge, this is the first study that determined the predictors of energy cost and found that habitual walking speed was the greatest contributor to the energy cost during stair ascent and descent. This finding is not surprising, since increases in habitual walking speed were related to higher functional status, and better perception of quality of life in individuals with stroke ${ }^{26)}$.

Although a previous study ${ }^{27)}$ demonstrated that individuals with stroke require higher strength levels of the paretic ankle plantar flexor muscles during stair ascent and descent, this variable was not retained in the model. Only the strength of the paretic knee extensor muscles was retained; it is well known that the knee extensor muscles play a dominant role in the progression from one step to the next during stair ascent. Thus, it is possible that higher demands on the weak knee extensor muscles resulted in increases in energy cost. However, while statistically significant, this added only $6 \%$ to the explained variance in the energy cost during stair ascent and descent. In this sense, when physiotherapists need to assess movement efficiency in terms of oxygen utilization during stair management, it is not mandatory to have a dynamometer to obtain strength measures. The measurement of habitual walking speed, which is low-cost, easy, and reliable ${ }^{17,18)}$ in individuals with stroke, should be enough to provide some insights regarding the energy cost during stair ascent and descent.

The distance covered during the 6MWT added only 5\% to the variance in the energy cost during stair ascent and descent. Although Combs et al. ${ }^{28)}$ found that walking farther is more important than walking faster to be able to better engage in activities both at home and in the community for individuals with chronic stroke, the results of the present study demonstrated that the distance covered during the 6MWT explained little of the variance during stair ascent and descent. This may be because it is unlikely that people with stroke are able to cover long distances when managing stairs. It is important to consider that accessibility in many countries is limited, and stairs are commonly found in most public places frequented by individuals with stroke ${ }^{9}$. 
Table 2. Predictors of energy cost during stair ascent and descent $(n=55)$

\begin{tabular}{|c|c|c|c|c|c|}
\hline Energy cost & $\mathrm{b}$ & $95 \% \mathrm{CI}$ for $\mathrm{b}$ & $\mathrm{b}$ & $\begin{array}{c}\text { Adjusted } \\
\mathrm{R}^{2}\end{array}$ & SEE \\
\hline \multicolumn{6}{|l|}{ Step 1} \\
\hline \multirow[t]{2}{*}{ Constant } & $2.18 \pm 0.19$ & 1.80 to 2.56 & - & - & - \\
\hline & & & & 0.47 & 0.33 \\
\hline \multirow[t]{3}{*}{ Habitual walking speed } & $-1.19 \pm 0.20$ & -1.60 to -0.78 & -0.69 & & \\
\hline & & & & - & - \\
\hline & & & & - & - \\
\hline \multicolumn{6}{|l|}{ Step 2} \\
\hline Constant & $1.92 \pm 0.20$ & 1.51 to 2.34 & - & 0.53 & 0.31 \\
\hline Habitual walking speed & $1.20 \pm 0.19$ & -1.58 to -0.82 & -0.70 & & \\
\hline Knee extensor strength & $0.27 \pm 0.01$ & 0.01 to 0.05 & 0.27 & - & - \\
\hline Step 3 & & & & - & - \\
\hline Constant & & 1.48 to 2.27 & - & - & - \\
\hline Habitual walking speed & $1.87 \pm 0.20$ & -1.27 to -0.13 & -0.33 & 0.58 & 0.29 \\
\hline Knee extensor strength & - & 0.01 to 0.05 & 0.30 & & \\
\hline \multirow[t]{4}{*}{ Distance covered } & $0.57 \pm 0.35$ & 0.01 to 0.05 & -0.43 & & \\
\hline & 0.03 & & & & \\
\hline & - & & & & \\
\hline & $0.01 \pm 0.01$ & & & & \\
\hline
\end{tabular}

* b: regression coefficients, followed by the respective standard error; CI: confidence interval; $b$ : standardized regression coefficient; $\mathrm{R}^{2}$ : coefficient of determination; SEE: standard error of the estimate. The regression equation was statistically significant $(\mathrm{p}<0.05)$. Energy cost $\left(\mathrm{ml} \cdot \mathrm{kg}^{-1} \cdot \mathrm{m}^{-1}\right)=1.87-0.57$ (habitual walking speed, in $\mathrm{m} / \mathrm{s}$ ) -0.01 (distance covered during the 6 -minute walking test, in $\mathrm{m}$ ) +0.03 (strength of the knee extensor muscles, in kgf)

The findings of the present study have important implications. First, clinical and low-cost measures of walking can be used to obtain information related to movement efficiency for important tasks for individuals with stroke. Evidence-based rehabilitation strategies that promote increases in walking speed, distance covered, and strength of the knee extensor muscles could be implemented, when the goal is to improve efficiency in terms of oxygen utilization during stair ascent and descent. Second, the developed equation could be used as an indicator of movement efficiency, in order to follow progress over the rehabilitation process. Thus, the use of the predictive equation for energy cost is very important, especially during chronic phases, and would enable clinicians to target specific and adequate levels of physical effort during intervention.

One could argue the fact that isometric, instead of concentric or eccentric strength measures, were assessed. However, we chose to assess isometric strength, because this measure can be easily reproduced by therapists in clinical settings ${ }^{22}$. In addition, all the participants were at chronic stages and could walk independently without walking aids. Therefore, the present findings could not be generalized to individuals with other characteristics.

The results of the present study demonstrated that habitual walking speed, strength of the paretic knee extensor muscles, and distance covered during the 6MWT together explained $58 \%$ of the variance in the energy cost during stair ascent and descent. Habitual walking speed was the most important predictor, and alone explained $47 \%$ of the variance. These findings could help rehabilitation professionals assess the energy cost during stair ascent and descent and plan interventions aimed at improving movement efficiency, based upon knowledge of the possible factors that could contribute to energy cost during stair ascent and descent.

\section{ACKNOWLEDGEMENT}

This work was supported by the Brazilian Government Funding Agencies (CAPES, CNPq, and FAPEMIG).

\section{REFERENCES}

1) Kafri M, Myslinski MJ, Gade VK, et al.: High metabolic cost and low energy expenditure for typical motor activities among individuals in the chronic phase after stroke. J Neurol Phys Ther, 2014, 38: 226-232. [Medline] [CrossRef]

2) Awad LN, Palmer JA, Pohlig RT, et al.: Walking speed and step length asymmetry modify the energy cost of walking after stroke. Neurorehabil Neural Repair, 2015, 29: 416-423. [Medline] [CrossRef]

3) Reisman DS, Binder-MacLeod S, Farquhar WB: Changes in metabolic cost of transport following locomotor training poststroke. Top Stroke Rehabil, 2013, 20: 161-170. [Medline] [CrossRef]

4) Mayo NE, Wood-Dauphinee S, Côté R, et al.: Activity, participation, and quality of life 6 months poststroke. Arch Phys Med Rehabil, 2002, 83: 1035-1042. [Medline] [CrossRef]

5) Kim K, Kim YM, Kim EK: Correlation between the activities of daily living of stroke patients in a community setting and their quality of life. $\mathrm{J}$ Phys Ther Sci, 2014, 26: 417-419. [Medline] [CrossRef]

6) Alzahrani MA, Dean CM, Ada L: Ability to negotiate stairs predicts 
free-living physical activity in community-dwelling people with stroke: an observational study. Aust J Physiother, 2009, 55: 277-281. [Medline] [CrossRef]

7) Prasomsri J, Jalayondeja C, Bovonsunthonchai S, et al.: Walking and stair climbing abilities in individuals after chronic stroke with and without mental health problem. J Med Assoc Thai, 2014, 97: S10-S15. [Medline]

8) Lee J, Seo K: The effects of stair walking training on the balance ability of chronic stroke patients. J Phys Ther Sci, 2014, 26: 517-520. [Medline] [CrossRef]

9) Pinheiro MB, Polese JC, Machado GC, et al.: The ability to manage stairs for chronic stroke survivors improves with increases in physical activity levels. J Nov Physiother, 2014, 3: 3.

10) Startzell JK, Owens DA, Mulfinger LM, et al.: Stair negotiation in older people: a review. J Am Geriatr Soc, 2000, 48: 567-580. [Medline] [CrossRef]

11) Roorda LD, Roebroeck ME, van Tilburg T, et al. Measuring Mobility Study Group: Measuring activity limitations in climbing stairs: development of a hierarchical scale for patients with lower-extremity disorders living at home. Arch Phys Med Rehabil, 2004, 85: 967-971. [Medline] [CrossRef]

12) Bertolucci PH, Brucki SM, Campacci SR, et al.: Suggestions for utilization of the mini-mental state examination in Brazil. Arq Neuropsiquiatr, 1994, 52: 1-7 [article in Portuguese]. [CrossRef]

13) Bohannon RW, Smith MB: Interrater reliability of a modified Ashworth scale of muscle spasticity. Phys Ther, 1987, 67: 206-207. [Medline]

14) Quinn TJ, Langhorne P, Stott DJ: Barthel index for stroke trials: development, properties, and application. Stroke, 2011, 42: 1146-1151. [Medline] [CrossRef]

15) Dohoo IR, Martin SW, Stryhn H: Veterinary Epidemiology Research. Charlottetown: University of Prince Edward Island, 2003, pp 296-315.

16) Wasserman K, Hansen JE, Sue DY, et al.: Clinical Exercise Testing. In Principles of Exercise Testing and Interpretation. Philadelphia: Lippincott Williams and Wilkins, 2005, pp 378-399.

17) Salbach NM, Mayo NE, Higgins J, et al.: Responsiveness and predictability of gait speed and other disability measures in acute stroke. Arch Phys Med Rehabil, 2001, 82: 1204-1212. [Medline] [CrossRef]
18) Nascimento LR, Caetano LC, Freitas DC, et al.: Different instructions during the ten-meter walking test determined significant increases in maximum gait speed in individuals with chronic hemiparesis. Rev Bras Fisioter, 2012, 16: 122-127. [Medline] [CrossRef]

19) Statement AT ATS Committee on Proficiency Standards for Clinical Pulmonary Function Laboratories: ATS statement: guidelines for the six-minute walk test. Am J Respir Crit Care Med, 2002, 166: 111-117. [Medline] [CrossRef]

20) Fulk GD, Echternach JL, Nof L, et al.: Clinometric properties of the sixminute walk test in individuals undergoing rehabilitation poststroke. Physiother Theory Pract, 2008, 24: 195-204. [Medline] [CrossRef]

21) Bohannon RW: Test-retest reliability of hand-held dynamometry during a single session of strength assessment. Phys Ther, 1986, 66: 206-209. [Medline]

22) Dorsch S, Ada L, Canning CG, et al.: The strength of the ankle dorsiflexors has a significant contribution to walking speed in people who can walk independently after stroke: an observational study. Arch Phys Med Rehabil, 2012, 93: 1072-1076. [Medline] [CrossRef]

23) Munro BH: Statistical methods for health care research. Philadelphia: Lippincott Williams \& Wilkins, 2005, pp 110-134.

24) Zamparo P, Francescato MP, De Luca G, et al.: The energy cost of level walking in patients with hemiplegia. Scand J Med Sci Sports, 1995, 5: 348-352. [Medline] [CrossRef]

25) Platts MM, Rafferty D, Paul L: Metabolic cost of over ground gait in younger stroke patients and healthy controls. Med Sci Sports Exerc, 2006, 38: 1041-1046. [Medline] [CrossRef]

26) Schmid A, Duncan PW, Studenski S, et al.: Improvements in speed-based gait classifications are meaningful. Stroke, 2007, 38: 2096-2100. [Medline] [CrossRef]

27) Novak AC, Brouwer B: Strength and aerobic requirements during stair ambulation in persons with chronic stroke and healthy adults. Arch Phys Med Rehabil, 2012, 93: 683-689. [Medline] [CrossRef]

28) Combs SA, Van Puymbroeck M, Altenburger PA, et al.: Is walking faster or walking farther more important to persons with chronic stroke? Disabil Rehabil, 2013, 35: 860-867. [Medline] [CrossRef] 